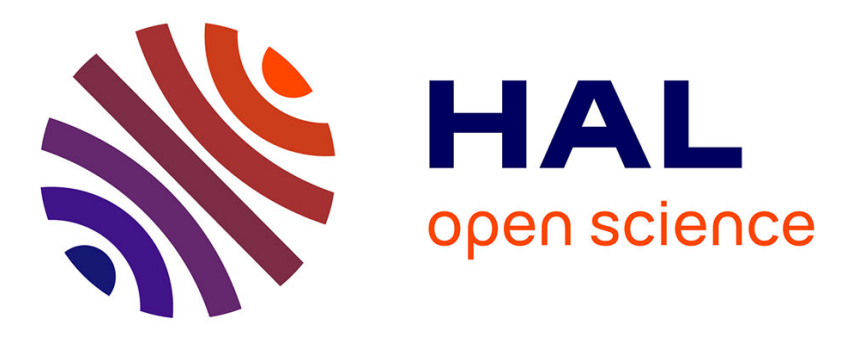

\title{
Influence of the anatase/rutile ratio on the charge transport properties of TiO 2 -NTs arrays studied by dual wavelength opto-electrochemical impedance spectroscopy
}

Thomas Cottineau, Hubert Cachet, Valérie Keller, Eliane Sutter

\section{To cite this version:}

Thomas Cottineau, Hubert Cachet, Valérie Keller, Eliane Sutter. Influence of the anatase/rutile ratio on the charge transport properties of TiO 2 -NTs arrays studied by dual wavelength optoelectrochemical impedance spectroscopy. Physical Chemistry Chemical Physics, 2017, 19 (46), pp.31469 - 31478. 10.1039/c7cp06270b . hal-01661650

\section{HAL Id: hal-01661650 \\ https: / hal.sorbonne-universite.fr/hal-01661650}

Submitted on 28 Nov 2019

HAL is a multi-disciplinary open access archive for the deposit and dissemination of scientific research documents, whether they are published or not. The documents may come from teaching and research institutions in France or abroad, or from public or private research centers.
L'archive ouverte pluridisciplinaire HAL, est destinée au dépôt et à la diffusion de documents scientifiques de niveau recherche, publiés ou non, émanant des établissements d'enseignement et de recherche français ou étrangers, des laboratoires publics ou privés. 


\title{
Journal Name
}

\section{ARTICLE}

\section{Influence of the anatase/rutile ratio on the charge transport
properties of $\mathrm{TiO}_{2}$-NTs arrays studied by dual wavelength opto- \\ Influence of the anatase/rutile ratio on the charge transport
properties of $\mathrm{TiO}_{2}$-NTs arrays studied by dual wavelength opto- electrochemical impedance spectroscopy.}

Received 00th January 20xx, Accepted 00th January 20xx

DOI: $10.1039 / \times 0 \times x 00000 x$

www.rsc.org/

\author{
T. Cottineau, ${ }^{a,+}$ H. Cachet, ${ }^{b}$ V. Keller ${ }^{a}$ and E. M. M. Sutter ${ }^{b}$
}

The modification of photo-generated charge transport properties in aligned titanium dioxide nanotube (TiO ${ }_{2}-\mathrm{NTS}_{\mathrm{s}}$ regarding the anatase/rutile ratio was studied by photo-electrochemical methods. $\mathrm{TiO}_{2}-\mathrm{NTs}_{\mathrm{T}}$ obtained by anodization were thermally treated under air flux at different temperatures to significantly modify the proportion of $\mathrm{TiO}_{2}$ anatase and rutile phase in the tubular structure. Material characterisation methods (XRD, SEM, UV-visible spectroscopy) were used to determine the characteristics of the different $\mathrm{TiO}_{2}$-NTs electrodes in terms of dimensions, proportion of each phases and optical properties. Solar to chemical energy conversion efficiency of these electrodes during an oxidation processes was investigated in basic aqueous solution, using methanol as sacrificial agent, by cyclic voltametry and Incident Photon to Current conversion Efficiency (IPCE) measurements. $\mathrm{TiO}_{2}$-NTs with a high rutile content absorb photon of higher wavelengths, but despite this red shifted optical band gap, they exhibit the lowest photo-electrochemical conversion efficiency. To further investigate the transport properties in these photoelectrodes, Intensity-Modulated Photocurrent Spectroscopy (IMPS) was used with two different irradiation wavelengths to determine the transport and recombination properties of anatase and rutile separetly. The results obtained by this set of experiment indicate that the presence of rutile at the bottom of the nanotubes is the major factor limiting the photo-generated electrons transfer.

\section{Introduction}

Despite the wide band gap of titanium dioxide $\left(\mathrm{E}_{\mathrm{g}} \approx 3.2 \mathrm{eV}\right)$ limiting its photoactivity in the UV domain of the solar spectrum, there is still a great interest in this material for lightdriven organic degradation and water splitting thanks to it good stability in a wide range of $\mathrm{pH}^{1,2,3}$ In order to enhance its photocatalytic performances, there is an intensive effort to develop new $\mathrm{TiO}_{2}$ nanostructures and modify their electronic properties by doping approaches with the aim to improve light absorption and photo-generated charge carrier separation. ${ }^{4,5,6}$ At the same time, there is an important need to study more in details fundamental aspects of the photo-electrochemical processes such as light absorption, photo-generated charges transport, catalysis of the reactions etc... ${ }^{7,8}$ This requires developing characterisation methods to investigate the properties of complex nanostructures.

Steady state photo-electrochemical methods are nowadays extensively used to characterise the behaviours of photo-

\footnotetext{
a. CNRS, Univ. Strasbourg, UMR 7515, Institut de Chimie et Procédés pour l'Energie, I'Environnement et la Santé, 25 rue Becquerel, F-67087 Strasbourg, France.

${ }^{b}$. Sorbonne Universités, UPMC Univ. Paris 06, CNRS, Laboratoire Interfaces et Systèmes Electrochimiques, 4 place Jussieu, F-75005, Paris, France.

+ Corresponding author: cottineau@unistra.fr

Electronic Supplementary Information (ESI) available: Evolution of the anatase and rutile crystallite size as a function of temperature. See DOI: 10.1039/x0xx00000x
}

electrodes under simulated solar irradiation conditions. Conversion efficiency calculation methods are well standardized and defined to compare results obtained on different materials by different research groups. ${ }^{9,10}$ The efficiency can be calculated through cyclic voltametry, or by calculating the yield of photocatalytic reactions. The spectral response of photo-electrodes is another important point that can be determined by calculating Incident Photon Conversion Efficiency (IPCE) using monochromatic irradiation. These experiments give overall conversion efficiency, however, In order to get more detailed information about the mechanisms involved in the reaction, it is important to determine charge carrier transport properties such as their mobility, recombination or transfer at the interface with electrolyte. These phenomena are often measured by ex-situ spectroscopic methods (pump-probe, transient photoluminescence etc....). ${ }^{11,12}$ Consequently, the obtained results are difficult to extrapolate to the conditions of the photoelectrochemical reactions when the material is in contact with an electrolyte and under an applied potential. In this perspective, opto-electronic impedance methods, such as intensity modulated photo-current/-voltage spectroscopy (IMPS/IMVS) appear as a powerful tool for the analysis of charge carrier dynamics in Photo-electrochemical (PEC) cells. This method was used to analyse the transport properties of hematite $\left(\alpha-\mathrm{Fe}_{2} \mathrm{O}_{3}\right)^{13,14}$ and $\mathrm{TiO}_{2}$ photoanodes ${ }^{15}$ thanks to the general IMPS analytical model proposed by Peter and Ponomarev. ${ }^{16}$ These studies usually investigated the influence 
of electrode potential, to identify trap states, ${ }^{13}$ or the influence of light intensity for non linear transport phenomenon. $^{17}$

In the case of $\mathrm{TiO}_{2}$, opto-electronic impedance method can provide useful information to explain the differences in the photocatalytic activities between the two main crystalline phases of $\mathrm{TiO}_{2}$ anatase and rutile. Their different behavior has often been discussed, yet mainly for nanoparticles of $\mathrm{TiO}_{2}$ which are extensively used in dye sensitized solar cell (DSCC), for solar fuel production ${ }^{18}$ and degradation of pollutants. ${ }^{19}$ While it is generally admitted that anatase has a higher activity than rutile in many photocatalytic reactions, the mechanisms of charge transfer depend on the morphology of the layer. In the case of nanopowders, Yamakata et al have used timeresolved visible to mid-IR absorption spectroscopy to elucidate the main reason for such a difference: ${ }^{20}$ They found that free electrons in anatase particles have lifetimes as long as $1 \mathrm{~ms}$, whereas the lifetime in rutile is only of a few picoseconds due to electron trapping in deep levels. Consequently the electrons in anatase are very reactive for reduction reactions, while in rutile, the extended life time of holes favors oxidation processes in absence of recombination. The higher activity of anatase in photocatalytic reactions arises then from the higher activity for $\mathrm{O}_{2}$ reduction since $\mathrm{O}_{2}{ }^{-}$anions radicals promote the oxidation of organic molecules.

The mechanisms of charge transfer are quite different in 1D aligned titanium dioxide nanotubes $\left(\mathrm{TiO}_{2}-\mathrm{NTs}\right)$ employed in photo-electrochemical configuration. In a nanotubular structure the separation between photo-generated holes and electrons is orthogonal: ${ }^{4}$ a space charge region is extending circularly in the side of the walls and in the depletion regime, holes are driven to the wall/electrolyte interface, whereas electrons are collected in the center of the wall and transported to the back contact. Consequently, holes have to be transported over a half wall thickness, which is comparable to their diffusion length in anatase $\mathrm{TiO}_{2}\left(L_{D} h^{+}{ }_{(T i O 2)} \approx 5-10\right.$ $\mathrm{nm}) .^{21,22}$ Meanwhile, negative charges have to be transported over the whole thickness of the nanotubular layer. An important point to consider in photo-electrocatalytic experiments with nanoporous layers is the good balance between nanotube lengths $(x)$, light penetration depth of the light $\left(L_{\lambda}\right)$ and electron diffusion length $\left(L_{D} e^{-}\right) . L_{\lambda}$ is related to the absorbance of $\mathrm{TiO}_{2}$ and is longer for photon with energy close to the band gap energy and shorter for photon of higher energy. In a compact anatase $\mathrm{TiO}_{2}$ layer a $L_{\lambda}$ of $1.3 \mu \mathrm{m}$ have been given at $350 \mathrm{~nm} .{ }^{23}$ But due to light scattering in $\mathrm{TiO}_{2}-\mathrm{NTs}$ layer, the absorption depth is expected to be shorter. To ensure the maximal photo-conversion efficiency, the aligned nanotube should be long enough to absorb a large number of photons but their length should not exceed $x=L_{\lambda}+L_{D} e^{-}$. As a consequence, the photo-response in $1 \mathrm{D}$ structure strongly depends on the electron transfer from the oxide to the substrate along the tube length. Electron transport in $\mathrm{TiO}_{2}$ has been shown to be influenced by the presence of energy traps inducing a hopping transfer (i.e. thermally activated trapping/detrapping processes). ${ }^{22}$ The hopping transfer process depends on the light intensity since photo-generated electrons will fill the available traps. This explains why electron transit time as long as 30s where measured for $\mathrm{TiO}_{2}-\mathrm{NTs}$ for a tube length of $11 \mu \mathrm{m}$ under low irradiation. ${ }^{17}$ The different energy of trapping level in anatase and rutile explains their differences in terms of electron diffusion length. ${ }^{24}$ Long electron diffusion lengths of over $20 \mu \mathrm{m}$ have been reported for anatase $\mathrm{TiO}_{2}$-NTs for DSSC, in which a high density of electron are injected from the dye to the $\mathrm{TiO}_{2}$ conduction band. ${ }^{25}$ In the case of photo-electrocatalytic applications, a shorter electron diffusion length is expected because of the lowest density of photo-generated electrons in the $\mathrm{TiO}_{2}$-NTs. Indeed, an optimal thickness of NTs film between 4 and $6 \mu \mathrm{m}$ of NTs were reported. ${ }^{26,27}$

The aim of the present work is to investigate the impact of the rutile phase on the rates of charge transfer and recombination in aligned $\mathrm{TiO}_{2}$-NTs using opto-electrochemical measurements. The electrochemical approach used for the synthesis allows growing $\mathrm{TiO}_{2}-\mathrm{NTs}$ with controllable and reproducible length ${ }^{4}$ and depending on the thermal annealing conditions, it is possible to crystallize the initially amorphous titania into anatase titanium dioxide and even rutile $\mathrm{TiO}_{2}$ at higher temperature. ${ }^{28}$ It was reported that the rutile phase is thermally formed at the metal/oxide interface underneath the tubes. ${ }^{29}$ Das et al. recently characterized by conductive AFM the transport properties of such films with different amounts of rutile. ${ }^{30}$ In this work we will investigate the dynamics of the photo-generated carriers directly in the photo-electrochemical cell by IMPS methods. By using two irradiation wavelengths and due to the small difference of the optical bandgap of the two phases, different depths in the $\mathrm{TiO}_{2}-\mathrm{NTs}$ layer are expected to be excited and characterized. IMPS measurements were performed at a wavelength close to the gap of anatase $(377 \mathrm{~nm})$ for which the charges are mainly generated in the top of the $\mathrm{TiO}_{2}-\mathrm{NTs}$ film and at a longer wavelength close to the band gap of rutile $(400 \mathrm{~nm})$ for which the charges are generated deeper in the layer. The dynamics of the photogenerated carriers were studied and discussed in the two conditions. The measurements were performed in the presence of methanol, a hole scavenger, in order to obtain an efficient collection of holes at the surface of the nanotubes and minimize surface recombination of holes with majority carriers. The dynamic photocurrent responses can then be discussed in terms of electron transport to the back contact involving trapping/detrapping from deep states.

\section{Experimental section}

\section{Preparation of $\mathrm{TiO}_{2}$ NT electrodes}

$\mathrm{TiO}_{2}$-NTs were synthesized from metallic titanium foil (99.6\%; MaTeck $\mathrm{GmbH}$ ) by electrochemical anodization. The metallic $\mathrm{Ti}$ surface were cleaned in 3 successive ultrasonic baths in acetone, ethanol and $\mathrm{H}_{2} \mathrm{O}$ (5 minutes each) and finally dried under $\mathrm{N}_{2}$ stream.

The electrolyte used for anodization was composed of ethylene glycol (99.5\% Sigma-Aldrich) containing $0.3 \%$ w/w $\mathrm{NH}_{4} \mathrm{~F}$ (98\%; Sigma-Aldrich) and $1 \% \%_{v} / v$ of ultrapure water. The 
anodization was conducted in a two electrode cell using a Biologic SP-300 potentiostat with a $48 \mathrm{~V}$ booster module. The electrolyte temperature was maintained constant at $25^{\circ} \mathrm{C}$ during the synthesis. The counter and working electrodes were a platinum foil and the cleaned $\mathrm{Ti}$ foil respectively. A first anodization was performed at $45 \mathrm{~V}$ during $2 \mathrm{~h}$ and the resulting nanotube film was pealed of with adhesive tape. This preanodization step results in a clean metallic $\mathrm{Ti}$ surface with small pits that improve the formation and adherence of the final $\mathrm{TiO}_{2}$-NTs film. ${ }^{31}$ The final anodization was conducted in the same conditions at $45 \mathrm{~V}$, and was stopped when the charge transferred reached $5 \mathrm{C} . \mathrm{cm}^{-2}$ to obtain a reproducible length.

After anodization, the nanotubes are thoroughly rinsed with ultrapure water and dried under $\mathrm{N}_{2}$ flux. In order to crystallize the amorphous nanotube layers were annealed during 4 hours in a tubular furnace under air flow $\left(100 \mathrm{~mL} \cdot \mathrm{min}^{-1}\right)$ at different temperatures. The heating and cooling ramps were $5^{\circ} \mathrm{C} \cdot \mathrm{min}^{-1}$.

\section{Materials Characterizations}

The morphological analysis of the $\mathrm{TiO}_{2}$-NTs was conducted employing a Scanning Electron Microscopy (FEG-SEM, JEOL $6700 F)$. The dimensions were evaluated using the Image $^{\circledR}$ software taking the mean value for the diameters and lengths of 10 NTs of each sample.

X-Ray Diffraction patterns (XRD) were measured in a classical $\theta / \theta$ configuration using a Bruker D8 equipped with a LynxEye PSD detector (Cu $\mathrm{K}_{\alpha} \lambda=0.15418 \mathrm{~nm}$ ). Temperature dependant XRD was performed in an Anton-Paar HTK 1200 temperature chamber. The $\mathrm{TiO}_{2}$-NTs film obtained after anodization was fixed to a corundum sample holder and the temperature was increased from room temperature to $800^{\circ} \mathrm{C}$ with a slope of $5^{\circ} \mathrm{C} \cdot \mathrm{min}^{-1}$. The XRD patterns were recorded in the 24 to $85^{\circ} 2 \theta$ range at several stages during which the temperature was kept constant for $45 \mathrm{~min}$.

Diffuse reflectance UV visible spectra were recorded on a Perkin-Elmer Lambda 950 spectrometer equipped with a 100 $\mathrm{mm}$ integration sphere.

\section{Photo-Electrochemical characterizations}

PEC measurements were conducted in aqueous solution of 0.2

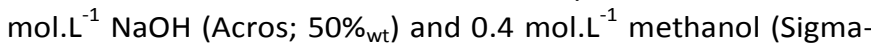
Aldrich; 99.9\%) as sacrificial agent for oxidation reaction. The $\mathrm{TiO}_{2}$-NTs film were used as a working electrode in a three electrode cell with $\mathrm{Pt}$ mesh as counter electrode and a mercury sulphate reference electrode $\left(\mathrm{MSE} ; \mathrm{E}_{\mathrm{MSE}}=\mathrm{E}_{\mathrm{NHE}}-640\right.$ $\mathrm{mV}$ ). All potentials are given with respect to the reversible hydrogen electrode (RHE). Cyclic Voltametry measurements were conducted between -0.3 and $1.6 \mathrm{~V}$ vs RHE at $50 \mathrm{mV} . \mathrm{s}^{-1}$ under illumination and in the dark, using a Biologic SP-300 potentiostat. The light source was a Xe arc lamp (Newport ${ }^{\circledR}$ $6655,300 \mathrm{~W}$ ) calibrated to obtain a power density of $60 \pm 2$ $\mathrm{mW} . \mathrm{cm}^{-2}$ reaching the sample.

The Incident Photon to Current conversion Efficiency (IPCE) was measured with a monochromated Xe arc light source using a Newport ${ }^{\circledR}$ Oriel $1 / 8 \mathrm{~m}$ Cornerstone Monochromator. The entrance and exit slits of the monochromator were set to obtain a resolution of $8 \mathrm{~nm}$. The power density arriving on the cell was monitored by a photodiode (Newport ${ }^{\circledR}$ PowerMeter 1918C) placed behind a beam splitter. A homemade LabView ${ }^{\circledR}$ program was used to control the measurements.

Intensity-Modulated Photo-current Spectroscopy (IMPS) was carried out using a Zahner CIMPS set-up equipped with two calibrated LED sources emitting at $377 \mathrm{~nm}$ and $400 \mathrm{~nm}$ wavelengths. The $\mathrm{TiO}_{2}-\mathrm{NT}$ electrode was illuminated through the electrolyte side and the light intensity was set at a steady state value of $5.26 \mathrm{~mW} \mathrm{~cm}{ }^{-2}$ (photon flux of $1.0 \times 10^{16} \mathrm{~s}^{-1} \mathrm{~cm}^{-2}$ ) at $\lambda=377 \mathrm{~nm}$ and of $16.0 \mathrm{~mW} \mathrm{~cm}^{-2}$ (photon flux of $3.2 \times 10^{16} \mathrm{~s}^{-1}$ $\mathrm{cm}^{-2}$ ) at $\lambda=400 \mathrm{~nm}$. A sinusoidal perturbation of $4 \%$ of the steady state irradiance was superimposed on the constant base light intensity for IMPS experiments. In IMPS experiments, potentials were measured against a silver reference electrode $(\mathrm{Ag} / \mathrm{AgCl})$, with a platinum wire as counter electrode. The different parameters involved in the selected IMPS models were obtained by a regression procedure based on a simplex strategy using the software SIMAD developed in the LISE laboratory.

\section{Results and discussion}

\section{$\mathrm{TiO}_{2}$-NTs characterizations}

By increasing the annealing temperature of $\mathrm{TiO}_{2}-\mathrm{NTs}$ samples, the $\mathrm{TiO}_{2}$ crystalline structure is expected to gradually change under thermal kinetic control from amorphous titanium oxide to anatase $\mathrm{TiO}_{2}$ and then to rutile phase. In order to determine the temperature range of these transitions, $X$ ray diffraction pattern of a pristine $\mathrm{TiO}_{2}$-NTs sample was recorded in situ at different temperatures up to $800^{\circ} \mathrm{C}$. The results presented in figure 1.a), exhibit no changes between 50 and $250^{\circ} \mathrm{C}$ and only the peaks attributed to $\mathrm{Ti}-\alpha$ from the metallic foil supporting amorphous nanotubes can be observed $(2 \theta=25.73,38.27$ and $40.16^{\circ}$ ). From $300^{\circ} \mathrm{C}$ the diffraction pattern of anatase appears and the peak intensities increase with temperature. When the temperature reaches $500^{\circ} \mathrm{C}$ the contribution of rutile phase is observable and increases continuously with temperature until the upper limit of $800^{\circ} \mathrm{C}$. The weight fraction of rutile $f_{R u}$ can be estimated from the area of the (101) reflexion peak of anatase $\left(A_{A} ; 2 \theta=25.34^{\circ}\right)$ and the (110) peak of rutile $\left(A_{R u} ; 2 \theta=\right.$ $27.42^{\circ}$ ) according to the following equation:

$f_{R u}=\frac{A_{R u}}{k A_{A}+A_{R u}}$

$K$ is a correction factor (0.52) taking into account the relative sensitivity of the two phases. This factor was determined experimentally by recording XRD patterns of anatase/rutile mixture with known amount of each phase. As observed in figure 1.b), the contribution of rutile increases exponentially from 450 to $800^{\circ} \mathrm{C}$ and reach a final value of $72 \%$ of rutile. It should be noticed that eq.1 was mainly applied for $\mathrm{TiO}_{2}$ powder. In the case of aligned $\mathrm{TiO}_{2}$-NTs grown on Ti foil, there is preferential crystallographic orientation along the [001] for rutile and [100] for anatase. ${ }^{32}$ Consequently, the mass proportions measured in our case give a clear tendency but 


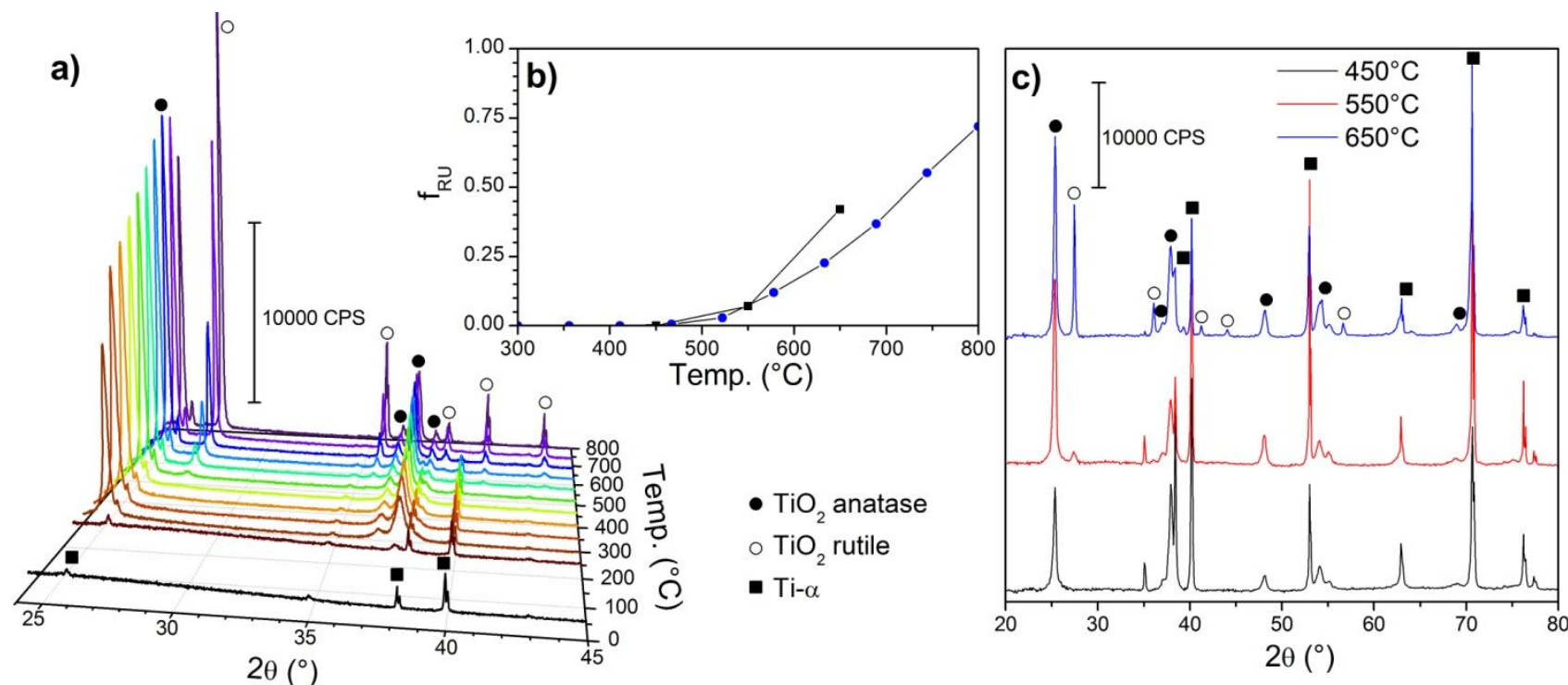

Figure 1: Temperature dependant X -ray diffraction patterns of $\mathrm{TiO}_{2}$-NTs grown on titanium foil (a) and XRD of the TiO $\mathrm{O}_{2}$-NTs samples annealed at the three different temperatures (c). The fraction of rutile phase depending on temperature for the in situ experiment (blue circles) and for the three samples prepare $d$ for PEC experiments (black squares) is represented (b).

cannot be considered as absolute values. Moreover, the repartition between rutile and anatase is not homogeneous. Indeed according to previous reports, rutile is likely to be formed mainly at the bottom of the tubes, by thermal oxidation of the titanium substrate. ${ }^{30,33}$ A rutile thickness up to $1 \mu \mathrm{m}$ was determined in a $2 \mu \mathrm{m}$ thick $\mathrm{TiO}_{2}$ NTs layer after annealing at $650{ }^{\circ} \mathrm{C} .{ }^{34}$ We used the Debye-Scherrer method to evaluate the size of the coherent crystalline domains of anatase and rutile from the width of diffraction peaks. ${ }^{35}$ The results are presented in ESI figure S1b. The crystallite width of anatase increases with the temperature from 15 to $28 \pm 2 \mathrm{~nm}$. For rutile, the crystallite size can only be measured above $500^{\circ} \mathrm{C}$, when the phase appears and the width increases much faster than for anatase from 10 to $50 \mathrm{~nm}$. The wall thickness of the $\mathrm{TiO}_{2}-\mathrm{NTs}$ measured by SEM measurement is ranging from 20 to $30 \mathrm{~nm}$. Consequently, the average size of rutile crystallite is only compatible with the bottom of the tubes, were the walls are thicker, ${ }^{36}$ and accordingly to the literature. ${ }^{29,30,33,34}$
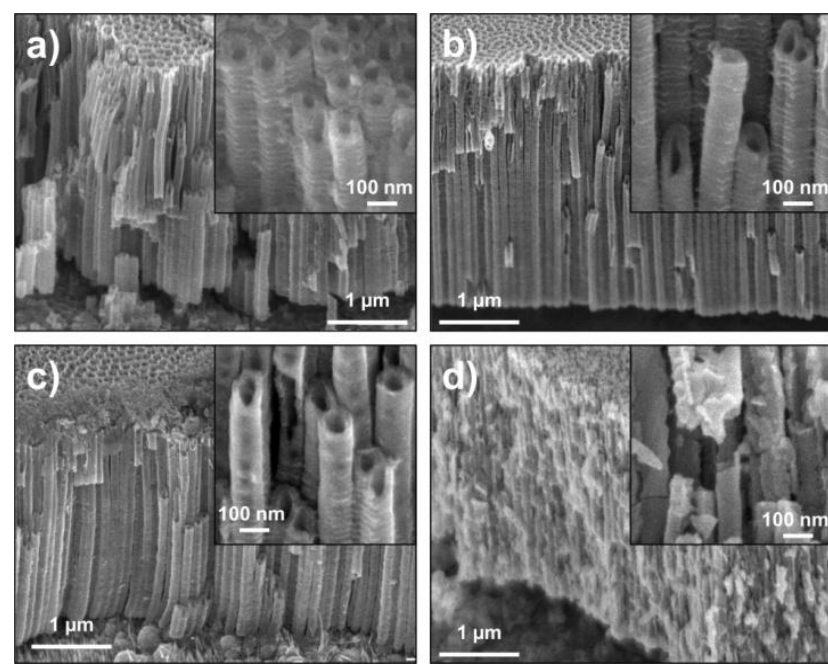

Figure 2: SEM images of $\mathrm{TiO}_{2}-\mathrm{NTs}$ samples synthesised at $45 \mathrm{~V}$ in ethylene glycol based electrolyte and annealed at $450^{\circ} \mathrm{C}(\mathrm{a}), 550^{\circ} \mathrm{C}(\mathrm{b}), 650^{\circ} \mathrm{C}$ (c) and $700^{\circ} \mathrm{C}(\mathrm{d})$.
Taking in consideration these results, three samples of $\mathrm{TiO}_{2}$-NTS were synthesized in similar anodization conditions and then annealed at $450^{\circ} \mathrm{C}, 550^{\circ} \mathrm{C}$ and $650^{\circ} \mathrm{C}$ to obtain different proportions of anatase and rutile. The minimum temperature of $450^{\circ} \mathrm{C}$ was chosen to obtain a sample with only anatase phase and the maximal temperature was limited to $650^{\circ} \mathrm{C}$ since higher temperature results in damaged nanotubes structure because of the volume change between anatase and rutile lattices (Fig. 2.d). The diffraction patterns of these samples are presented in figure 1.c. As expected, no diffraction peaks of the rutile phase appear for the sample annealed at $450^{\circ} \mathrm{C}$. The sample annealed at $550^{\circ} \mathrm{C}$ and $650^{\circ} \mathrm{C}$ presented a mixture of the two phases, with $7 \%$ and $42 \%$ of rutile respectively. The deviation in the rutile ratio between the sample and the in situ experiment around $650^{\circ} \mathrm{C}$ can be explained by different quantity of heat transferred in the two experiments (i.e. steady state versus transient heating; calibration of thermocouple etc...)

The morphology of the $\mathrm{TiO}_{2}$ nanotubes after thermal treatment was observed by SEM, with an observation angle of $45^{\circ}$, on the edge of the $\mathrm{TiO}_{2}$-NTs layer (Fig. 2). The samples annealed at three different temperatures (Fig 2.a, b and C) present similar morphology and close dimensions, reported in table 1 , with a length around $4 \mu \mathrm{m}$. The external and internal diameters $\left(D_{\text {out }}\right.$ and $\left.D_{\text {in }}\right)$ are around 100 and $50 \mathrm{~nm}$ respectively. The external diameter slightly diminish from 107 \pm 6 to $93 \pm 9 \mathrm{~nm}$ while the internal one increases when the temperature increase. Consequently the wall thickness decreases from 30 to $21 \mathrm{~nm}$. With this value we are able to calculate a specific surface area for the samples considering the surface developed by the $\mathrm{TiO}_{2}$-NTs packed in a compact hexagonal arrangement and the density of $\mathrm{TiO}_{2}{ }^{31}$ The obtained value of $20 \pm 3 \mathrm{~m}^{2} \cdot \mathrm{g}^{-1}$ is in good agreement with BET measurements conducted with krypton on a $\mathrm{TiO}_{2}-\mathrm{NTs}$ film $\left(21.1 \pm 0.5 \mathrm{~m}^{2} \cdot \mathrm{g}^{-1}\right)$. 

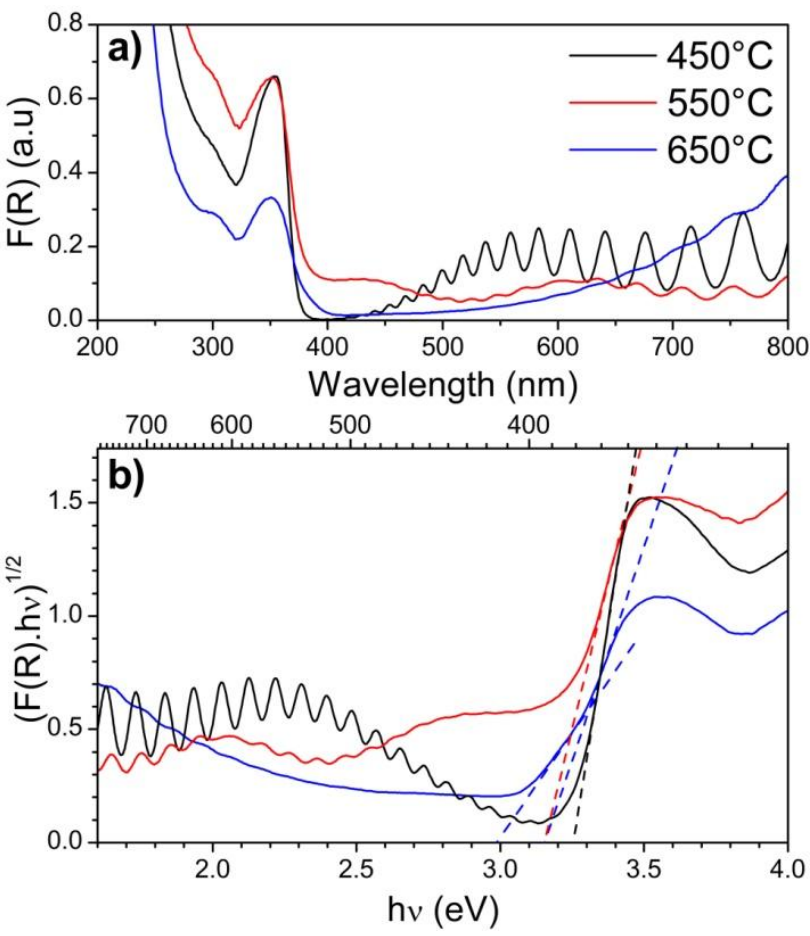

Figure 3: Diffuse reflectance data of the $\mathrm{TiO}_{2}-\mathrm{NTs}$ samples annealed at 450, 550 and $650^{\circ} \mathrm{C}$. (a) Kubelka-Munk function and (b) Tauc plot for bandgap calculation.

\section{UV-visible spectroscopy}

The light absorption properties of $\mathrm{TiO}_{2}$-NTs samples annealed at different temperatures were measured by diffuse reflectance spectroscopy. Figure 3.a represents the KubelkaMunk function calculated from the reflectance $R$, according to: ${ }^{37}$

$F(R)=\frac{(1-R)^{2}}{2 R}$

The Kubelka-Munk function can be considered as an equivalent of the absorption for thin films materials. In the visible range of the spectra $(\lambda>400 \mathrm{~nm})$, the NTs film present a non zero absorption that can be explained by two phenomena. First, $\mathrm{TiO}_{2}$-NTS films are annealed with the titanium foil whose colour changes during the thermal treatment and contribute to the light absorption and explains the difficult baseline subtraction. Secondly, the interference fringes typical of thin film materials can be observed, mainly for the sample at $450^{\circ} \mathrm{C}$, they originate from interferences between photons reflecting at the $\mathrm{TiO}_{2}$-NTs surface and those reflected at the $\mathrm{Ti}$ interface after propagating in the film. ${ }^{38}$ These oscillations indicate the high level of organisation and the homogeneous length of the $\mathrm{TiO}_{2}$-NTs tubes. These interference fringes can be used to estimate the thickness $d$ of the film from the wavelengths of the peak $m\left(\lambda_{m}\right)$ and the peak $m+x\left(\lambda_{m+x}\right)$ according to:

$d=\frac{x \lambda_{m} \lambda_{m+x}}{2\left(\lambda_{m} \sqrt{n f_{\lambda m+x}^{2}-n_{a}^{2} \sin ^{2} \theta}-\lambda_{m+x} \sqrt{n f_{\lambda m}^{2}-n_{a}^{2} \sin ^{2} \theta}\right)}$

with $\theta$ the angle of incidence, $n_{a}$ the refractive index of the incidence medium ( $n_{a}=1$ for air) and $n f_{\lambda}$ the film refractive index at a given wavelength. The film refractive index was calculated considering a porosity of $60 \%$ and from the value reported for an anatase thin film. ${ }^{39}$ The thickness calculation was made for the 5 peaks at higher wavelength of each sample and was found to be in good agreement with the SEM measurements with values ranging from $4010 \pm 130 \mathrm{~nm}$ for the sample annealed at $450^{\circ} \mathrm{C}$ to $3800 \pm 100 \mathrm{~nm}$ for the one at $650^{\circ} \mathrm{C}$.

The apparent band gap $E_{G}$ of the semi-conductor film was calculated from the Tauc plot (figure 3.b.) by the intercept of the abscise axis with the straight line defined by equation 4 :

$F(R)=A \frac{\left(h v-E_{G}\right)^{m}}{h v}$

for an indirect bandgap material, like $\mathrm{TiO}_{2}$ anatase, $m=2$. $A$ is a constant whose value is determined by the maximum of the first derivative of Tauc curves. For the $\mathrm{TiO}_{2}-\mathrm{NTS}$ samples containing anatase exclusively the bandgap has a value of 3.26 $\pm 0.05 \mathrm{eV}$ and the samples annealed at $550^{\circ} \mathrm{C}$ present a slightly reduced $E_{G}$ value of $3.17 \pm 0.05 \mathrm{eV}$. These values are consistent with the one reported in the literature for anatase $\mathrm{TiO}_{2}{ }^{40}$ In the case of the sample annealed at $650^{\circ} \mathrm{C}$, two linear domains appear on the Tauc plot (fig. 3.c blue). They correspond to bandgap energies of $3.15 \pm 0.05$ and $2.99 \pm 0.06 \mathrm{eV}$ which can be attributed to anatase and rutile crystallites in the $\mathrm{TiO}_{2}$ nanotubes respectively. The two distinctive bandgaps can be observed only for the sample annealed at $650^{\circ} \mathrm{C}$ thanks to its high proportion of rutile.

Table 1: Physical Characteristics of the $\mathrm{TiO}_{2}$-NTs samples annealed at different temperature.

\begin{tabular}{|c|c|c|c|c|}
\hline Anneal Temp. & Length $(\mu \mathrm{m})$ & $D_{\text {out }}(\mathrm{nm})$ & $D_{\text {in }}(\mathrm{nm})$ & $E_{g}(\mathrm{eV})$ \\
\hline $450^{\circ} \mathrm{C}$ & $4.04 \pm 0.16$ & $107 \pm 6$ & $47 \pm 6$ & 3.26 \\
\hline $550^{\circ} \mathrm{C}$ & $4.14 \pm 0.10$ & $98 \pm 11$ & $48 \pm 9$ & 3.17 \\
\hline $650^{\circ} \mathrm{C}$ & $4.06 \pm 0.15$ & $93 \pm 9$ & $51 \pm 5$ & $3.15 / 2.99$ \\
\hline
\end{tabular}

\section{Photo-Electrochemical measurements}

Cyclic voltametry results of the 3 electrodes, recorded under irradiation and in the dark, are presented in figure 4.a and 4.b. The CV exhibit the same shape with the photocurrent increasing for potential higher than $0 \mathrm{~V}$ vs RHE and reaching a plateau around $0.5 \mathrm{~V}$. For the samples annealed at 450 and $550^{\circ} \mathrm{C}$ the maximum photo-current reaches approximately 3.0 $\mathrm{mA} \cdot \mathrm{cm}^{-2}$. The higher annealing temperature results in a reduced photo-current of $2.3 \mathrm{~mA} . \mathrm{cm}^{-2}$. Additionally, the slope of the curve between 0 and the maximum photo current is slightly reduced indicating a more resistive behaviour of the electrode. For comparison, we added the cyclic voltametry for the sample annealed at $450^{\circ} \mathrm{C}$ in the absence of methanol. The shape is similar, but the photocurrent is strongly reduced. The higher photocurrent measured in the presence of methanol is explained by the fact that the (photo-)electrocatalytic oxidation of $\mathrm{MeOH}$ is an easier reaction than water oxidation (i.e. 2 vs $4 \mathrm{e}^{-}$process). Consequently, holes are more efficiently used for oxidation, minimizing their recombination with photogenerated electrons. 

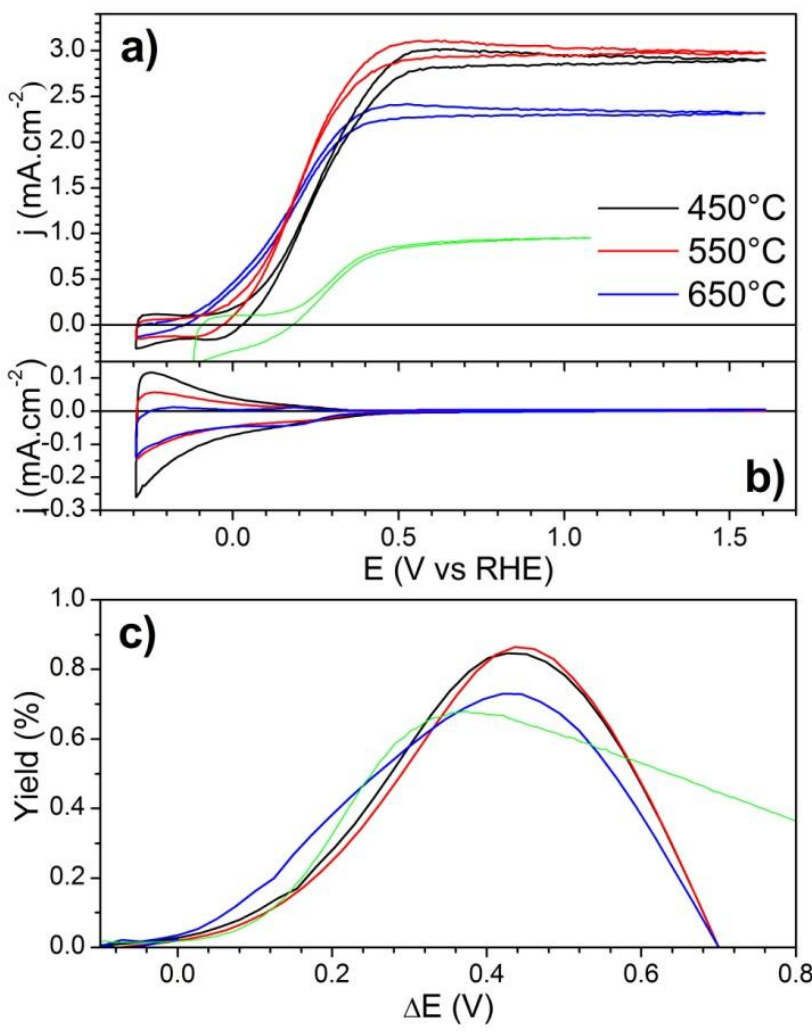

Figure 4: Cyclic voltamograms of $\mathrm{TiO}_{2}$-NTs photo-anodes annealed at 450, 550 and $650 \mathrm{C}$ in 2 mol. $\mathrm{L}$. photo-anode annealed at $450^{\circ} \mathrm{C}$. (c) Corresponding ABPE of the 3 electrodes.
phot

From these data the Applied Bias Photon to current Efficiency (ABPE) of each electrode can be calculated to compare the efficiency of the different electrodes according to: ${ }^{41}$

$A B P E=\frac{j_{p h}\left(E_{r e v}-\Delta E\right)}{P_{l u m}}$

with $j_{p h}$ the photocurrent, $\Delta E$ the bias voltage defined as the difference between the applied voltage at the working electrode and the open circuit potential of the photo-anode under illumination. $E_{r e v}$ is the thermodynamic potential corresponding to the reaction, namely $1.23 \mathrm{~V}$ for water splitting. In the case of $\mathrm{MeOH}$ oxidation, the value of $0.7 \mathrm{~V}$ reported in the literature for oxidation into $\mathrm{CO}_{2}$ was used. ${ }^{42}$

Figure 4.c shows the ABPE of the different electrodes and confirms the best performances of $\mathrm{TiO}_{2}-\mathrm{NTS}$ thermally treated at 450 and $550^{\circ} \mathrm{C}$.

By using monochromatic irradiation in photoelectrochemical experiments, it is possible to determine IPCE that can be defined as the ratio between the number of collected electrons and the number of incident photons on the cell according to equation 6 :

$\operatorname{IPCE}(\lambda)=\frac{h \cdot c}{e}\left(\frac{j_{p h}(\lambda)}{P(\lambda) \cdot \lambda}\right)$

$j_{p h}(\lambda)$ and $P(\lambda)$ are the measured photocurrent and the incident light power density at a given wavelength $\lambda$, respectively. IPCE values of the three samples are reported in figure 5 . In figure 5.a, one can observe the same tendency than the one
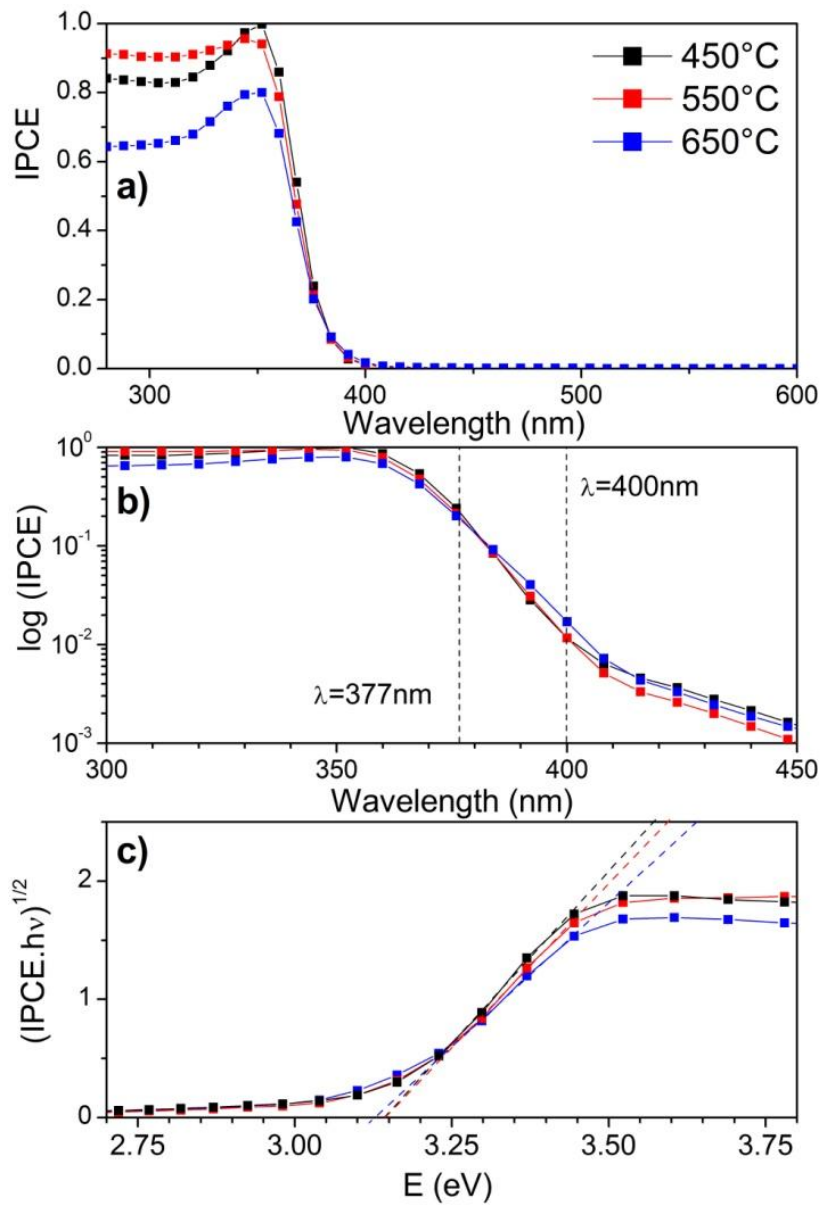

Figure 5: Incident Photon to Electron Conversion Efficiency of the three samples (a), representation in logarithmic scale of the $300-450 \mathrm{~nm}$ spectral domain (b) and Tauc plot of the IPCE (c)

observed on cyclic voltametry: the samples annealed at 450 and $550^{\circ} \mathrm{C}$ present higher conversion efficiency than the one at $650^{\circ} \mathrm{C}$ and they achieve a quantum yield close to $97 \pm 2 \%$ at $355 \mathrm{~nm}$. With this IPCE representation all samples appear to absorb in the same spectral domain while on UV-visible spectra the contribution of rutile was observable. On figure 5.b IPCE is represented in logarithmic scale and it is possible to distinguish the small contribution of rutile around $400 \mathrm{~nm}$. At this wavelength the IPCE of the sample annealed at $650^{\circ} \mathrm{C}$ is $40 \%$ higher than the one of the two other samples. The two vertical dashed lines in figure 5.b correspond to the wavelength of the LEDs used for irradiation in IMPS experiments discussed in the last part of the manuscript.

An equivalent of Tauc plot was calculated from IPCE: from these values it is possible to determine a photo-conversion bandgap. Accordingly to what was previously mentioned, only the contribution of anatase appears and we can determine a band-gap of $3.14 \pm 0.03 \mathrm{eV}$ for all samples.

In order to check the consistency between CV (full spectrum of Xe lamp) and IPCE (monochromatic irradiation) measurements, the latest is integrated and convoluted with the Xe lamp spectra according to:

$j_{I P C E}=\frac{e}{h \cdot c} \int_{\lambda_{\min }}^{\lambda_{\max }} \operatorname{IPCE}(\lambda) P_{X e}(\lambda) \lambda \cdot d \lambda$ 
$P_{x e}(\lambda)$ is the power density of the Xe lamp at a given wavelength. $J_{I P C E}$ is then the value of photocurrent expected for the Xe lamp at the potential used for IPCE measurements (1V vs RHE). It should be equivalent to the photocurrent measured by $\mathrm{CV}$ at the same potential. With $J_{\text {IPCE }}$ values of 2.85, 2.90 and $2.29 \pm 0.05 \mathrm{~mA} . \mathrm{cm}^{-2}$, for samples annealed at 450,550 and $650^{\circ} \mathrm{C}$ respectively, the difference with cyclic voltametry results is less than $5 \%$ confirming the reliability of the different steady state measurements.

\section{Intensity modulated photocurrent spectroscopy measurements}

IMPS technique combines a strong continuous irradiation with a small sinusoidal modulation of light intensity in order to determine the values of rate constants for charge transfer and recombination. ${ }^{13}$ IMPS data are presented in figure 6 for the 3 samples measured at 375 and $400 \mathrm{~nm}$ at different potentials. It clearly appears that for the sample annealed at $450^{\circ} \mathrm{C}$ (anatase), the Bode diagrams poorly depend on the applied potential in a wide potential range. On the contrary in the case of rutile containing electrodes, the diagrams show a strong dependence on the applied potential and the evolution is more pronounced when the rutile content increases.

Theoretical models of IMPS have been proposed and successfully applied for different materials. ${ }^{16}$ In this work, only two elementary steps were considered for the photocurrent: direct charge transfer and recombination (rate constants $k_{t r}$ and $k_{\text {rec }}$, respectively). Within these conditions, the analytical expression of the ac component of the photocurrent has been derived by Ponomarev et al as following: ${ }^{15,16}$

$j(\omega)=$

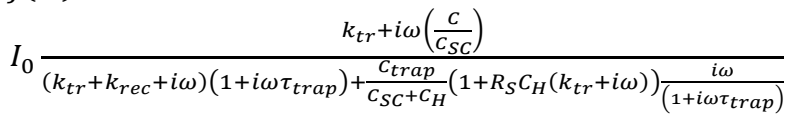

where $I_{o}$ is the amplitude of the modulated photocurrent, $C_{\mathrm{sc}}$ the space charge layer capacitance, $C_{H}$ the Helmoltz layer capacitance, $C$ the interfacial capacitance (equation 9)

$C=\frac{C_{S C} C_{H}}{C_{S C}+C_{H}}$

$C_{\text {trap }}$ is an additional contribution of surface states not involved in recombination and $\tau_{\text {trap }}=R_{\text {trap }} C_{\text {trap }}$. From equation (8) it is seen that the real part of $j(\omega)$ at $\omega=0$ tends towards $I_{o} k_{t r} /\left(k_{t r}+k_{\text {rec }}\right)$.

Eq. 8 was used for fitting of the results using the SIMAD software. Two values $R_{\mathrm{s}}$ and $I_{o}$ were fixed, limiting the number of adjustable parameters to 6 . The $R_{s}$ value was determined previously from EIS measurements and the $I_{o}$ value was taken at the lowfrequency intercept of the single semicircle at $E=1.77 \mathrm{~V}$ vs RHE), at which it is assumed that surface recombination are minimized and can be fully neglected. To check the reliability of the rate constants determined by IMPS, we have verified that for each case the calculated current $I_{0} k_{t r} /\left(k_{t r}+k_{\text {rec }}\right)$ which represents the amplitude of the modulated photocurrent is well proportional to the steadystate photocurrent $j_{\text {photo }}$. As represented in figure 7.a and b, for both illumination wavelengths close values are obtained. The evolutions of $k_{t r}$ (charge transfer rate), $k_{\text {rec }}$ (recombination rate) as a function of applied potential are reported in Figure 7.c and d, for the three annealing temperatures and the two wavelengths. For the anatase sample, the transfer rate constant $k_{\text {tr }}$ presents a plateau for potentials positive to $1.07 \mathrm{~V}$ vs RHE), in agreement with the photocurrent plateau. The value of the plateau decreases when the rutile content increases. Under sub-bandgap illumination, $k_{t r}$ increases linearly with potential, the higher the slope, the higher the rutile content. The recombination rate constant $k_{\text {rec }}$ presents a decreasing exponential behavior with potential in the different cases. The variations of $C_{s c}$ with potential were analyzed on the basis of the previously developed electrical model taking into account the nanotubular geometry] providing an estimation of the carrier density $\left(5.10^{19} \mathrm{~cm}^{-3}\right)$ and of the flat band potential $E_{f b}=+$ $0.37 \pm 0.05 \mathrm{~V}$ vs RHE (Not shown). ${ }^{43}$
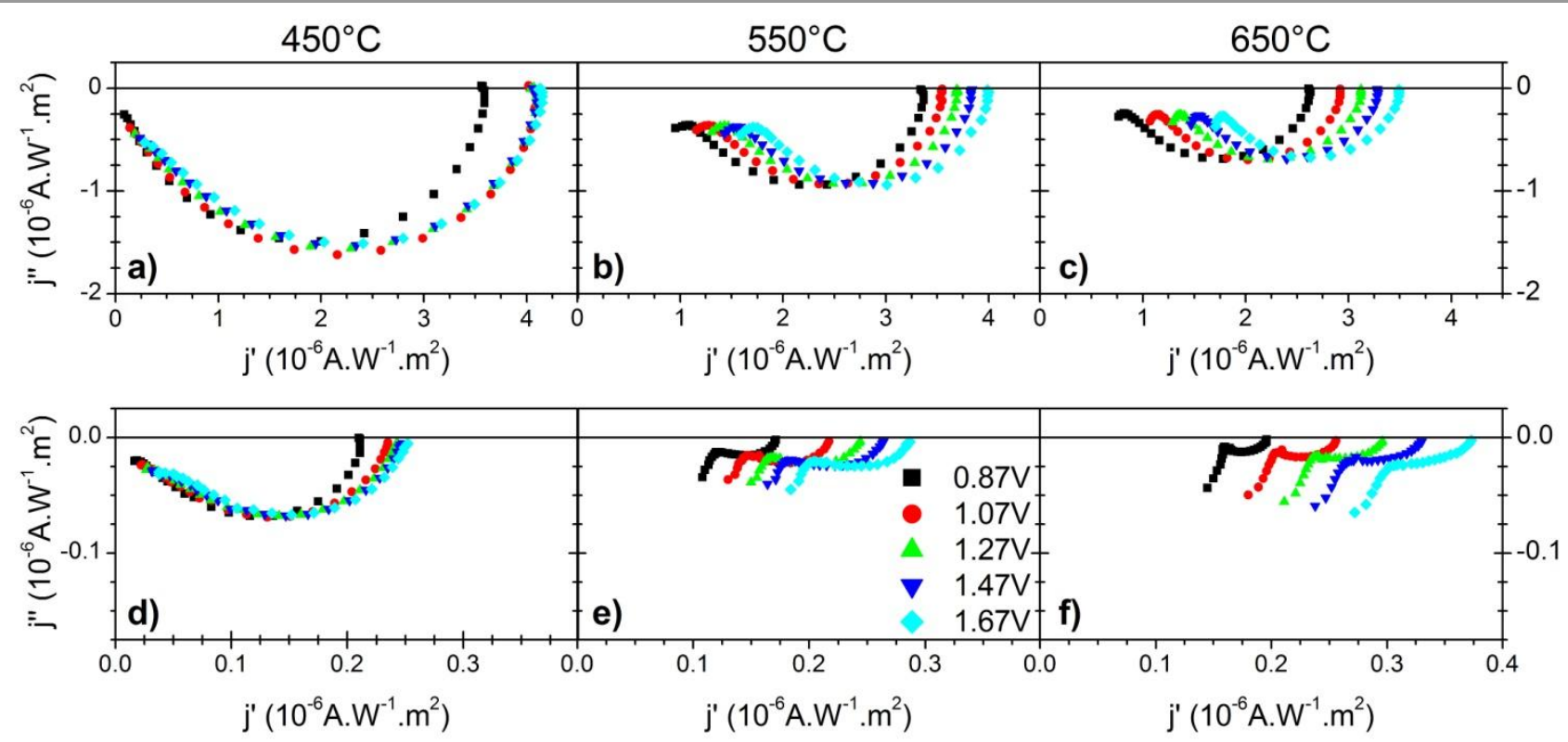

Figure 6: IMPS data of the $\mathrm{TiO}_{2}-\mathrm{NTS}$ samples annealed at 450,550 and $650^{\circ} \mathrm{C}$. The illumination wavelength was $377 \mathrm{~nm}$ for a, b and $\mathrm{c}$ and $400 \mathrm{~nm}$ for $\mathrm{d}$, e and $\mathrm{f}$. 

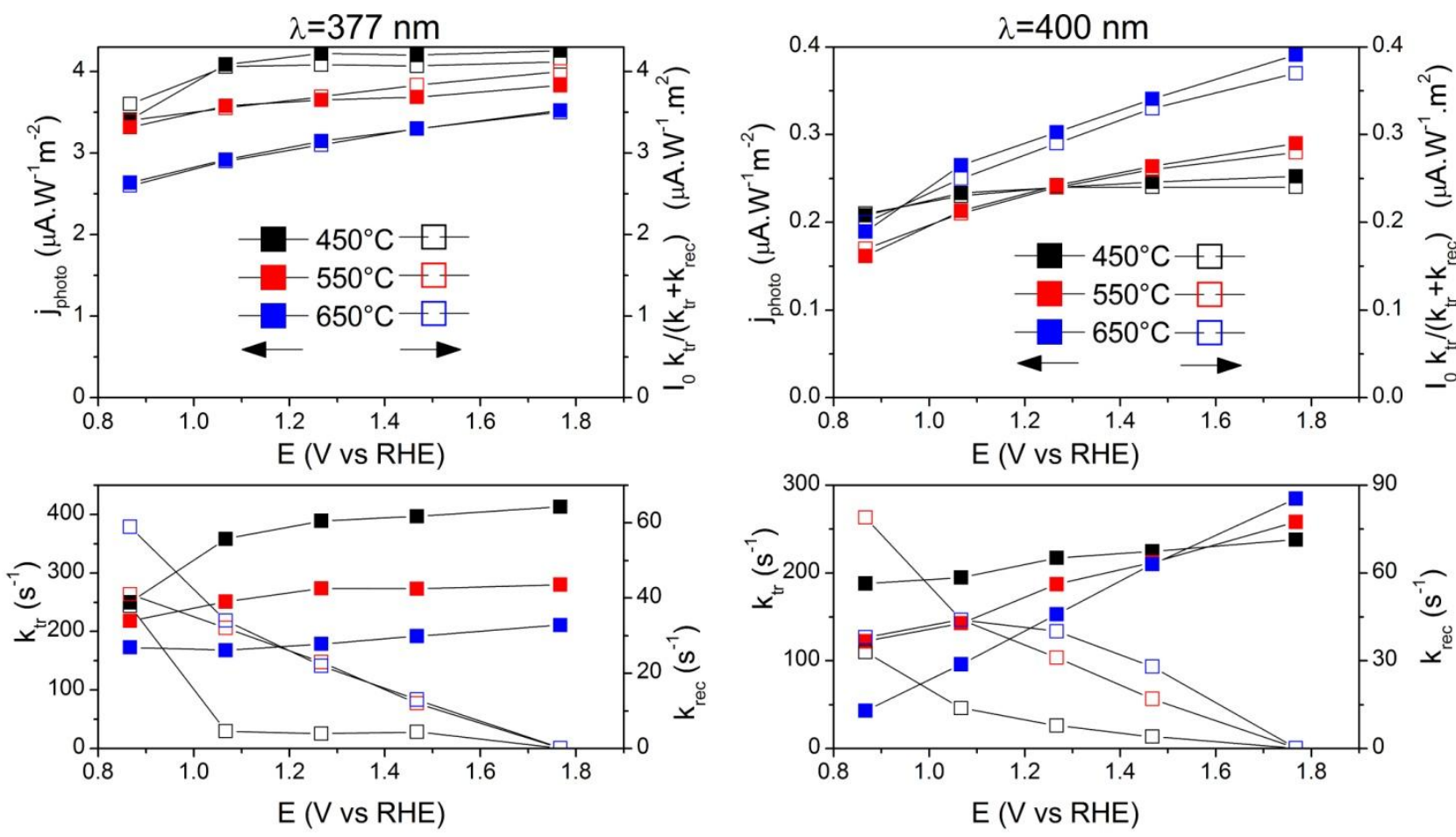

Figure 7: Data treatment of IMPS measurement at $377(\mathrm{a}, \mathrm{c})$ and $400 \mathrm{~nm}(\mathrm{~b}, \mathrm{~d})$. Steady state photocurrent and $\mathrm{I}_{0} k_{t r} /\left(k_{t r}+k_{r e c}\right)$ ratio as a function of the applied potential (Figure 7.a and b); evolution of $k_{t r}$ and $k_{\text {rec }}$ for the $\mathrm{TiO}_{2}$-NTs annealed at 450,550 and $650^{\circ} \mathrm{C}$ (figure 7.c and d.)

At wavelength close to the band gap value $(377 \mathrm{~nm})$, only the outermost part of the NT layer is absorbing light, consequently, the photogenerated charges are created in this zone. Holes are collected at the surface of the tubes while electrons are diffusing to the back contact. The space charge layer which is situated in the wall region of the tube gets progressively depleted with increasing bias. Due to the short diffusion path of holes in the tube wall (half the wall width, between 15 and $10 \mathrm{~nm}$ in the present case), saturation of the photocurrent is expected already at a relatively small bias. This is clearly observed in the sample annealed at $450^{\circ} \mathrm{C}$ (Fig 7.a) at potentials positive to $1.07 \mathrm{~V}$ vs RHE. Another consequence of the short diffusion path of holes in NT layers is that the hole transfer is a very fast process. The rate constant $k_{t r}$ is then likely to concern mainly electron transfer towards the back contact. $k_{\text {rec }}$ provides a global description of the surface recombination kinetics between photogenerated charges, with an exponential but non ideal behaviour with the applied potential $E$. The recombination rates $k_{\text {rec }}$ are found to be proportional to $\exp \left[-e\left(E-E_{f b}\right) /\left(m k_{B} T\right)\right]$ with $m$ much larger than unity, the larger is $m$, the higher is the annealing temperature. This is due to the difference of trapping level energy in anatase and in rutile phases: anatase presents shallow trap levels, while rutile shows deeper traps, slowing down the electron transfer by hopping process. ${ }^{17,24}$ This is reflected by comparing the values of IPCE at $377 \mathrm{~nm}$ with the evolution of the $k_{t r}$ at $377 \mathrm{~nm}$. ICPE values are $0.240,0.214$ and 0.202 for samples annealed at 450,550 and $650^{\circ} \mathrm{C}$ respectively, corresponding to a decrease of $15 \%$ when the annealing temperature is increased. A similar decrease is observed for $j_{\text {photo }}$ but at the same time $k_{t r}$ is reduced by $50 \%$ from $400 \mathrm{~s}^{-1}$ and $200 \mathrm{~s}^{-1}$. This observation suggests that almost the same quantities of photon are absorbed by the $\mathrm{TiO}_{2}$-NTs (mainly at their surface) to generate electrons, but the increasing amount of rutile present at the bottom of the nanotubes slows down their transport towards the back contact. Furthermore it can be noted that when the amount of rutile increases, $k_{t r}$ is less and less depending on the applied potential. This suggests that the electron transport in that case will not depend on the collection in the space charge layer, but is mainly limited by the conductivity of the rutile fraction at the bottom of the nanotubes.

The photoconversion efficiency of $\mathrm{TiO}_{2}-\mathrm{NTs}$ at $400 \mathrm{~nm}$ is strongly reduced when compared to the one at $377 \mathrm{~nm}$, whatever the annealing temperature. Nevertheless, the activity stays $50 \%$ higher in rutile rich sample (Fig 5). Since the penetration depth of light increases and anatase absorbs less photons than rutile at this wavelength, charge carriers are likely to be generated in rutile located at the bottom of the NTs film. In Fig 7.d, the evolution of $k_{t r}$ for the pure anatase sample at $400 \mathrm{~nm}$ exhibits a poor dependence on the applied potential. It is noticeable that $k_{t r}$ value is strongly reduced at $400 \mathrm{~nm}$ when compared to $377 \mathrm{~nm}$ values (from $400 \mathrm{~s}^{-1}$ to $200 \mathrm{~s}^{-1}$ ). This can be explained by the lower light absorption at $400 \mathrm{~nm}$ : less photo-generated electrons are available to fill the trapping levels in anatase and consequently the conductivity of NTs by hopping process decreases. ${ }^{22}$ When the rutile ratio increases, the potential dependence of $k_{t r}$ is more and more obvious. For the sample annealed at $650{ }^{\circ} \mathrm{C}$, in which rutile phase is dominant, $k_{t r}$ has a linear dependence on potential, passing from 40 to $300 \mathrm{~s}^{-1}$. It even reaches a higher value than for anatase when the applied potential increases. This linear dependence of $k_{t r}$ with potential can be correlated with a possible potential distribution along the tubes due to the increased material resistivity. Considering the linear variation of the steady state photocurrent with potential a rough estimate of the corresponding resistance would be about $3 \mathrm{k} \Omega \mathrm{cm}^{2}$. 


\section{Conclusions}

Different characterization methods were used to study the influence of the annealing temperature on the crystalline and photo-electrochemical properties of $\mathrm{TiO}_{2}$-NTs obtained by anodization. Temperature dependent $\mathrm{X}$ ray diffraction allowed us to identify the transition between amorphous, anatase and rutile phase and to estimate the amount of each phase in the different nanotube films. Optical spectroscopy was used to determine how the amount of rutile in the sample affects the optical bandgap. It evolved from 3.26 to $2.99 \mathrm{eV}$ when the amount of rutile increased. In the case of sample annealed at $650^{\circ} \mathrm{C}$, identified as the high temperature limit for a stable nanotubular structure, two different bandgaps appeared at 3.15 and $2.99 \mathrm{eV}$ that were attributed respectively to distinctive anatase and rutile domains.

These different samples were characterized by photoelectrochemical methods, showing that the performance of the $\mathrm{TiO}_{2}$-NTs electrode decreases for high ratio of rutile in the nanotubes. The PEC spectral responses of the different electrodes were measured by ICPE indicating no specific changes in the photoconversion, with a apparent band gap value of $3.14 \mathrm{eV}$, whatever the annealing temperature. A closer look on the IPCE data around $400 \mathrm{~nm}$ shows a small improvement of the photo-conversion efficiency due to the presence of rutile.

To further study this aspect, frequency dependent photoelectrochemical method was used. By measuring the IMPS response at two different wavelengths of irradiation it was possible to highlight the influence of rutile on the charge transfer in $\mathrm{TiO}_{2}$-NTs layer. Given that the rutile phase is located at the bottom of the tubes and given the difference of light absorption between anatase and rutile phases, by using irradiation at $377 \mathrm{~nm}$ mainly the anatase phase at the top of the nanotubes photogenerate charge carriers. On the contrary at $400 \mathrm{~nm}$ which allows deeper penetration of light, the overall photo-electrochemical response is dominated by the rutile. The main conclusions from IMPS experiments emphasize that in the different situations, the value of the photocurrent is directly determined by the rate of electron transport towards the metallic substrate. When the amount of rutile increases an additional resistance at the bottom of the tubes lowers the transfer rate.

The present work shows that IMPS operated with several excitation sources is a powerful tool for characterizing spatially distributed biphasic photo-electrochemical systems and to provide information about photogenerated charge carrier transport properties in such a nanostructured semi-conductors layers.

\section{Acknowledgements}

This work was funded by the University of Strasbourg through an IdEX project (CODoTiN) and ANR JCJC program (BAGETE). Thierry Dintzer and Thierry Romero are gratefully acknowledged for the XRD and SEM measurements.

\section{Notes and references}

1 N. S. Lewis, M. G. Walter, E. L. Warren, J. R. McKone, S. W. Boettcher, Q. Mi and E. A. Santori, Chem. Rev., 2010, 110, 64466473.

2 S. U. M. Khan, M. Al-Shahry and W. B. Ingler Jr., Science, 2002, 297, 2243-2245.

3 F. E. Osterloh, Chem Soc Rev, 2013, 42, 2294-2320.

4 P. Schmuki, K. Lee and A. Mazare, Chem. Rev., 2014, 114, 93859454.

5 T. Cottineau, N. Béalu, P.-A. Gross, S. N. Pronkin, N. Keller, E. R. Savinova and V. Keller, J. Mater. Chem. A, 2013, 1, 2151.

6 J. J. Brancho and B. M. Bartlett, Chem. Mater., 2015, 27, 72077217.

7 M. Kapilashrami, Y. Zhang, Y.-S. Liu, A. Hagfeldt and J. Guo, Chem. Rev., 2014, 114, 9662-9707.

8 K. Sivula and R. van de Krol, Nat. Rev. Mater., 2016, 1, 15010.

9 A. Murphy, P. Barnes, L. Randeniya, I. Plumb, I. Grey, M. Horne and J. Glasscock, Int. J. Hydrog. Energy, 2006, 31, 1999-2017.

10 L. M. Peter, Electroanalysis, 2015, 27, 864-871.

11 Y. Tamaki, A. Furube, M. Murai, K. Hara, R. Katoh and M. Tachiya, Phys. Chem. Chem. Phys., 2007, 9, 1453.

12 Y. Yamada and Y. Kanemitsu, Appl. Phys. Lett., 2012, 101, 133907.

13 L. M. Peter, J. Solid State Electrochem., 2013, 17, 315-326.

14 L. M. Peter, K. G. U. Wijayantha and A. A. Tahir, Faraday Discuss, 2012, 155, 309-322.

15 H. Cachet and E. M. M. Sutter, J. Phys. Chem. C, 2015, 119, 25548-25558.

16 E. A. Ponomarev and L. M. Peter, J. Electroanal. Chem., 1995, 396, 219-226.

17 R. P. Lynch, A. Ghicov and P. Schmuki, J. Electrochem. Soc., 2010, 157, G76.

18 Y. Ma, X. Wang, Y. Jia, X. Chen, H. Han and C. Li, Chem. Rev., 2014, 114, 9987-10043.

19 S. Banerjee, D. D. Dionysiou and S. C. Pillai, Appl. Catal. B Environ., 2015, 176-177, 396-428.

20 A. Yamakata, J. J. M. Vequizo and H. Matsunaga, J. Phys. Chem. C, 2015, 119, 24538-24545. 
21 P. Salvador, J. Appl. Phys., 1984, 55, 2977-2985.

22 T. Luttrell, S. Halpegamage, J. Tao, A. Kramer, E. Sutter and M. Batzill, Sci. Rep., , DOI:10.1038/srep04043.

23 D. Reyes-Coronado, G. Rodriguez-Gattorno, M. E. EspinosaPesqueira, C. Cab, R. de Coss and G. Oskam, Nanotechnology, 2008, 19, 145605.

24 B. Moss, K. K. Lim, A. Beltram, S. Moniz, J. Tang, P. Fornasiero, P. Barnes, J. Durrant and A. Kafizas, Sci. Rep., , DOI:10.1038/s41598017-03065-5.

25 J. R. Jennings, A. Ghicov, L. M. Peter, P. Schmuki and A. B. Walker, J. Am. Chem. Soc., 2008, 130, 13364-13372.

26 C. B. Marien, T. Cottineau, D. Robert and P. Drogui, Appl. Catal. B Environ., 2016, 194, 1-6.

27 X. Zhang, K. Huo, L. Hu, Z. Wu and P. K. Chu, J. Am. Ceram. Soc., 2010, 93, 2771-2778.

28 D. A. H. Hanaor and C. C. Sorrell, J. Mater. Sci., 2011, 46, 855874.

29 S. P. Albu, H. Tsuchiya, S. Fujimoto and P. Schmuki, Eur. J. Inorg. Chem., 2010, 2010, 4351-4356.

30 S. Das, R. Zazpe, J. Prikryl, P. Knotek, M. Krbal, H. Sopha, V. Podzemna and J. M. Macak, Electrochimica Acta, 2016, 213, 452459.

31 J. M. Macak, S. P. Albu and P. Schmuki, Phys. Status Solidi RRL Rapid Res. Lett., 2007, 1, 181-183.

32 P. Acevedo-Peña, F. González, G. González and I. González, Phys Chem Chem Phys, 2014, 16, 26213-26220.

33 A. Tighineanu, S. P. Albu and P. Schmuki, Phys. Status Solidi RRL - Rapid Res. Lett., 2014, 8, 158-162.

34 S. Ozkan, A. Mazare and P. Schmuki, Electrochimica Acta, 2015, 176, 819-826.

35 J. I. Langford and A. J. C. Wilson, J. Appl. Crystallogr., 1978, 11, 102-113.

36 T. Cottineau, S. N. Pronkin, M. Acosta, C. Mény, D. Spitzer and V. Keller, Sens. Actuators B Chem., 2013, 182, 489-497.

37 P. Kubelka, JOSA, 1948, 38, 448-448.

38 G. L. Chiarello, A. Zuliani, D. Ceresoli, R. Martinazzo and E. Selli, ACS Catal., 2016, 6, 1345-1353.

39 A. Bendavid, P. J. Martin and H. Takikawa, Thin Solid Films, 2000, 360, 241-249.
40 D. O. Scanlon, C. W. Dunnill, J. Buckeridge, S. A. Shevlin, A. J. Logsdail, S. M. Woodley, C. R. A. Catlow, M. J. Powell, R. G. Palgrave, I. P. Parkin, G. W. Watson, T. W. Keal, P. Sherwood, A. Walsh and A. A. Sokol, Nat. Mater., 2013, 12, 798-801.

41 Z. Chen, T. F. Jaramillo, T. G. Deutsch, A. Kleiman-Shwarsctein, A. J. Forman, N. Gaillard, R. Garland, K. Takanabe, C. Heske, M. Sunkara, E. W. McFarland, K. Domen, E. L. Miller, J. A. Turner and H. N. Dinh, J. Mater. Res., 2010, 25, 3-16.

42 T. Iwasita, Electrochimica Acta, 2002, 47, 3663-3674.

43 P. Pu, H. Cachet, E. Ngaboyamahina and E. M. M. Sutter, J. Solid State Electrochem., 2013, 17, 817-828. 